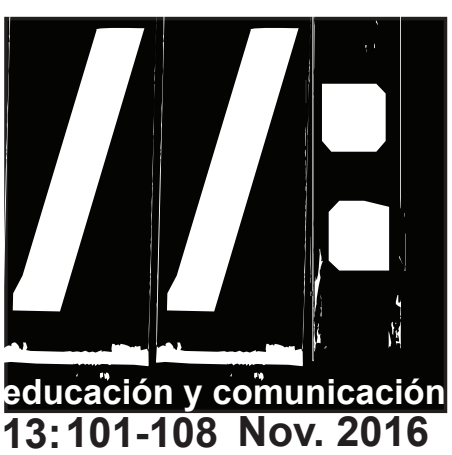

\section{ANARQUISMO EN LA EDUCACIÓN, EDUCACIÓN EN EL ANARQUISMO. UNA APROXIMACIÓN}

\section{Anarchism in Education, education in anarchism. An approach}

\author{
José Manuel Mato Ortega \\ Licenciado en Historia y Humanidades \\ Profesor de Enseñanza Secundaria. Cádiz (España) \\ E.mail: josemanuelmato@gmail.com
}

Resumen:

El artículo trata sobre la relación entre anarquismo y educación en España. Aborda tanto la propensión del anarquismo hacia la tarea educativa como herramienta social y revolucionaria como el tratamiento que del anarquismo se hace en el sistema educativo español actual. Para el primer tema se traza un breve acercamiento historiográfico sobre el tema. Para el segundo, principalmente, se ha acudido al análisis de libros de texto de Secundaria y Bachillerato. Palabras clave: Anarquismo, educación, anarcosindicalismo, escuelas libres, revolución, Educación Secundaria, Historia de España, olvido.

\title{
Abstract
}

The article deals with the relationship between anarchism and education in Spain. It addresses both the propensity of anarchism towards educational duties as a social and revolutionary tool as the treatment of anarchism is made in the current Spanish educational system. For the first topic a brief historiographical approach on the issue is drawn. For the latter, meanly, Secondary Education and High school textbooks had to be consulted for further analysis. Key words: Anarchism, education, anarcho-syndicalism, free education, revolution, High Scholl, History of Spain, oblivion.

Recibido: 20-05-2016 / Revisado: 07-06-2016 / Aceptado: 10-07-2016 / Publicado: 01-11-2016 


\section{II: Derechos humanos educación y comunicación}

\section{Introducción}

$\mathrm{E}$ anarquismo ibérico fue mucho más que la caricatura a la que se ve reducido: caos y violencia. En vísperas de la guerra civil la CNT contaba con 700.000 afiliados, todo un movimiento de masas. El anarcosindicalismo fue una de las principales herramientas de las que se valieron los libertarios españoles, pero no fue la única. Una de las labores principales del movimiento fue la tarea educativa.

Hasta el primer tercio del siglo XX, las escasas instituciones educativas estaban en manos de la Iglesia y el analfabetismo era la norma. La burguesía liberal intentó resolver este problema a través de la Institución Libre de Enseñanza educando a las élites. El movimiento obrero, y en especial el anarquista, abordarían una ingente tarea de educación popular. Para el anarquismo la educación era la llave de la revolución. Además de mostrar querencia por el autodidactismo, los sindicatos de la CNT eran considerados la "Universidad del Obrero" pues allí la clase trabajadora encontraría las herramientas organizativas e intelectuales para conseguir su emancipación (1); en los Ateneos Libertarios se realizaban una importante labor cultural. La educación racionalista de Ferrer i Guardia y su Escuela Moderna, levantó escuelas por toda la geografía. Las revistas donde se exponían al proletariado las innovaciones científicas o sociológicas completaron la tarea; destaca en ellas la participación directa de obreros mediante narrativa, lo que demuestra lo fructífero de la apuesta educativa libertaria (2). Para el establishment era preocupante: en el montaje de la Mano Negra, uno de los ejecutados fue el maestro Juan
Ruíz; a Ferrer i Guardia, que no estaba en Barcelona durante los sucesos, se le ejecutó como instigador de la Semana Trágica; en los primeros compases de la guerra, eliminaron al chiclanero Rodríguez Barbosa y al grazalemeño, Sánchez Rosa, autor de libros de formación para los obreros.

\section{La educación y la enseñanza}

Los gobiernos progresistas de la Segunda República intentaron acabar con los problemas de la enseñanza prohibiendo a la Iglesia su ejercicio, proyectando la creación de nuevas escuelas y a través de las misiones pedagógicas. Cuando se inició la guerra y, con ella, la Revolución (el Estado se derrumbó, allí donde no triunfó el golpe, y fue sustituido por organismos revolucionarios), la labor educativa libertaria continuó. La CNT y la FIJL realizaron cursos de alfabetización: "Milicias contra el analfabetismo en Aragón", "Brigadas de cultura al Campo" y "cursos por correspondencia". Se crearon bibliotecas y centros culturales en los pueblos colectivizados, colonias para niños refugiados, escuelas racionalistas, ateneos, escuelas de formación profesional y Artes y se organizaron cinefórums, talleres y espectáculos teatrales (3). Muchas iniciativas corrían a cargo de colectivos y organizaciones: Mujeres Libres, cuyo objetivo era emancipar a la mujer de su triple esclavitud (ignorancia, género y clase) y, para ello, se organizaron clases de cultura general, de capacitación profesional y de maternidad consciente (funcionamiento del organismo femenino, formación moral, amorosa y solidaria), liberatorios de prostitución, y publicó su revista, que vino a sumarse al amplio espectro de publicaciones anarquistas. En 


\section{1/: Anarquismo en la educación, educación en el anarquismo. Una aproximación}

Cataluña se coordinaron a través del CENU (Consell de l'Escola Nova Unificada).

En contraste con aquella labor educativa, el conocimiento que hay en la actualidad sobre el movimiento anarquista y sobre la Revolución Española es mínimo, y eso aun teniendo en cuenta que la Guerra Civil es el segundo tema sobre el que más se ha escrito (4). Esto genera un problema de comprensión de la Historia de la España Contemporánea, pues ésta no puede entenderse sin atender a un movimiento íntimamente enraizado en la misma y que formaba parte de la cultura radical que proponía alternativas de progreso para la atrasada España de la época.

\section{Sobre los libros de texto}

Analizando libros de texto de Secundaria podemos comprobar que abunda un discurso sobre el anarquismo bastante esquemático, incorrecto y distorsionado. La filosofía anarquista se explica mal (5); la historia del anarquismo español se centra en los tópicos (6) mientras que se sobredimensiona el papel del PSOE y la UGT (7); y, cuando se aborda la política interna de la zona republicana durante la guerra, aunque necesariamente se señala la Revolución (8), se refleja de manera difusa cuando no se presenta como algo exótico, ya que al no haber sido explicado el movimiento parece no tener razón de ser. No se aborda la obra constructiva (9), subrayándose solo el capítulo represivo (10) o el apartado político (11), partiéndose de la idea de que obedeció a extremismos (12).

Los libros de texto, no obstante, son solo uno de los recursos con los que se cuenta en la enseñanza. La cuestión de fondo es que el desconocimiento y la incomprensión son generalizadas. La represión y el exilio acabaron con toda una generación implicada en el cambio social, y el silencio obligado provocó el olvido de las ideas de emancipación social, favoreciendo, si acaso, a los marxismos, por la obsesión del régimen con el modelo del "socialismo real"; la Transición, con su política de olvido, volvería a dejar este capítulo de la Historia en la cuneta. A esto se suma el desconocimiento sobre el tema que padece, en general, el profesorado de Ciencias Sociales de Secundaria debido a que la formación universitaria es muy deficiente en este sentido. Un sondeo entre varias promociones de estudiantes de Historia en la UCA nos dará muestra de ello (13). Por último, hay que enmarcar esta realidad educativa en el papel que tiene la escuela en la reproducción del sistema (14), que la aleja de enseñar planteamientos que suponen una enmienda a la totalidad al mismo y, tal como se demostró en la Revolución del 36, una alternativa plausiblemente viable. Esta reproducción encierra, además, una proyección histórica: el sistema actual es el "menos malo de los sistemas posibles", por lo que las esperanzas y luchas de los revolucionarios de antaño, aunque bienintencionadas (en el mejor de los casos), fueron erradas y no muy dignas de mención.

\section{Notas}

(1) Peirats sobre Pedro Ara: "y su escuela fue la CNT, una CNT romántica, de pueblo, que habitaban idealistas, una biblioteca elemental $\mathrm{y}$, tal vez, una escuela libre. Tuvo una cultura precipitada, sin método, voluntarista y autodidacta, saturada de mística de redención y de generosidad estoica (...) así se formaban nuestros militantes de base, que eran el 


\section{II: Derechos humanos educación y comunicación}

esqueleto, la carne y el nervio de una gran familia" (Marín, 2010, pp. 318). “...la mayoría de las veces la educación se desarrollaba desde los medios más cercanos de que disponían los colectivos y sindicatos, puesto que las necesidades educativas más urgentes las sentían los afiliados mismos a las organizaciones, que sentían que debían instruirse para prepararse en la lucha contra el Capital y el Estado (...) Otra razón (...) era simplemente práctica: crear una escuela libertaria (...) era costoso y tropezaba con innumerables trabas administrativas. (...) La preocupación por la educación pasó a formar parte del orden del día de los congresos de la CNT. Ya en el de Barcelona de 1910 se dictaminó la necesidad de crear escuelas dentro de los sindicatos obreros..." (Cuevas, 2003, pp. 124129).

(2) Una de las publicaciones más destacadas en este sentido fue la Novela Ideal de la familia Montseny (Gutiérrez, 1998, pp. 15-30).

(3) (Tiana, 1987)

(4) (Gutiérrez, 1993, pp. 9). De los estudios sobre la Guerra Civil Española, salvo aquéllas obras que se dedican expresamente a la cuestión militar (batallas, equipamientos, modificaciones en los frentes...) todas las demás, de una manera más o menos profunda han tocado el tema de la Revolución.

(5) En algunos libros de texto de secundaria se estudia por una parte el marxismo, calificado como 'socialismo' (por la forma característica de organización marxista en los primeros compases del movimiento obrero: el Partido Socialista) y por otra el anarquismo, olvidando que ambas tendencias parten de un mismo tronco, el socialismo, autoritario uno y antiautoritario el otro. El anarquismo queda reducido en las lecciones a la búsqueda de la libertad individual, minimizando su carácter galvanizador de la libertad y la igualdad, del individuo y la sociedad. Por ejemplo: Anónimo, 2011; Díaz y otros, 2008, pp. 118; Sánchez, 1999, pp. 88; García De Cortázar y otros, 2003, pp. 260; Burgos y Muñoz-Delgado, 2008, pp. 75. En este libro, el apartado dedicado al movimiento obrero a partir de la disolución de la I Internacional borra de un plumazo al anarquismo (p. 90). Lo difuso de la presentación de las ideas libertarias, por ejemplo, aquí: "Los anarquistas se oponían al Estado y aspiraban a sustituirlo por algún tipo de asociación voluntaria entre las personas. También rechazaban la política, los partidos políticos y la participación en elecciones" (Grence y otros, 2008, pp. 70).

(6) Sobre la clase trabajadora en la Andalucía decimonónica se afirma que "sus difíciles condiciones de vida produjeron dos reacciones: la propagación del anarquismo (con acciones violentas) y el desarrollo del bandolerismo" (Díaz y otros, 2008, pp. 119). Sobre las primeras décadas del reinado de Alfonso XIII y sus problemas: “(el) terrorismo anarquista, que actuó, sobre todo, contra los políticos (...) y contra los empresarios de Barcelona, quienes respondieron formando escuadras armadas" (Idem, pp. 157); lo cierto es que el pistolerismo anarquista surgió en respuesta al pistolerismo del Sindicato Libre, formado por la patronal, ante las victorias sindicales, por ejemplo, tras que se consiguiera la jornada de 8 horas con la 'Huelga de la Canadiense' en 1919. La edición de Anaya de 2016 sentencia: "Era partidario de la acción directa, llevada a cabo con métodos violentos, como demuestra la actuación de la Mano Negra, una organización secreta que actuó en la comarca de Jerez" (Burgos y Muñoz-Delgado, 2016, pp. 184). Sobre este particular hay que señalar que existe consenso entre 


\section{1/: Anarquismo en la educación, educación en el anarquismo. Una aproximación}

los historiadores respecto a que la Mano Negra nunca existió y fue un montaje perpetrado por las autoridades para cortar el creciente asociacionismo campesino. En el libro de $2^{\circ}$ de Bachillerato de Santillana sí que encontramos mención a la inclinación anarquista por la enseñanza: "La estrategia política anarquista se centró en tres tipos de acciones: La acción violenta (...). La acción sindical (...). La producción cultural" (García De Cortázar y otros, 2003, pp. 260-262) en ese orden.

(7) Por ejemplo, dándose a conocer a su fundador, Pablo Iglesias mientras el silencio rodea a una figura como la de Anselmo Lorenzo. Anónimo, 2011, pp. 88; Grence y otros, 2008, pp. 111; Matesanz y otros, 2008, pp. 191; García De Cortázar y otros, 2003, pp. 262.

(8) En todos los consultados excepto en Matesanz y otros, 2008, pp. 210-211, además de Díaz y otros, 2008, pp. 183-184.

(9) Un extenso análisis y exposición de la obra constructiva de la Revolución Social Española en: Diez, 2003 y Kelsey, 1994.

(10) "En la zona republicana, se produjo una revolución social que supuso la colectivización de tierras e industrias y multitud de desordenes" (Burgos y Muñoz-Delgado, 2008, p. 152). "Bajo la influencia anarquista se formaron Comités, órganos de poder popular, que colectivizaron fábricas y latifundios. Todo símbolo aristocrático, burgués o religioso era perseguido y podía ser motivo de encarcelamiento o de muerte" (Anónimo, 2011, pp. 142).

(11) "El Gobierno se vio debilitado por la división entre los anarquistas y los comunistas radicales, que querían realizar primero la revolución para ganar la guerra, y los comunistas, que querían ganar la guerra para hacer la revolución” (Burgos y Muñoz-Delgado, 2008, pp. 152); "En la zona republicana, el Estado se desarticuló y emergieron múltiples y dispersos poderes revolucionarios. Estos pusieron en marcha una dura represión que pronto degeneró en terror. Grupos de milicianos persiguieron brutalmente a sus enemigos reales o supuestos" (García De Cortázar y otros, 2003, pp. 354).

(12) Con respecto a los libros de texto de la ESO, los de $2^{\circ}$ de Bachillerato (Historia de España) abordan la cuestión, lógicamente, de manera más amplia. No obstante se repiten los parámetros. Aunque se mencionan las colectividades rurales e industriales no se valora el incremento de la producción y su capacidad para mantener los frentes, y no se mencionan otras cuestiones como la fundación de hospitales y centros sanitarios o la labor educativa, y el planteamiento general es que fue obra de extremistas: "Las experiencias de autogestión, la autonomía de las columnas de milicianos en los frentes de guerra y la imposición de un cierto 'terror' revolucionario en las calles estuvieron impulsadas, sobre todo, por el sector más radical del anarcosindicalismo (CNT-FAI) y del POUM. El resto de fuerzas políticas mantuvieron muy pronto posiciones críticas, reclamando la necesidad de un poder estatal fuerte que concentrara sus esfuerzos en ganar la guerra" (García, Gatell, 2012, pp. 334). Como excepción, García De Cortázar y otros, 2003, pp. 350-356, que da algunas cifras y menciona la gestión de "numerosas empresas de servicios públicos, ferrocarriles y transportes urbanos".

(13) El realizado, sin ánimo de exhaustividad, para este artículo corresponde a las promociones 1996-2000, 1999-2003 y 2008-2014. En ninguno de ellas se estudió la Revolución Española (ni la 


\section{II: Derechos humanos educación y comunicación}

Guerra Civil, capítulo imprescindible de nuestra Historia). Y otras asignaturas como "Ideologías y Partidos Políticos en la España Contemporánea" o "Andalucía Contemporánea" solo tangencialmente mencionaban al anarquismo, cuando debiera ocupar un lugar destacado. Tampoco parece que la Pedagogía Libertaria, de la que la Escuela Moderna es un ejemplo primordial, encuentre demasiado hueco en los programas de los grados de Magisterio, como no lo encuentra en el Máster de profesorado ni se hace apenas mención a la organización Mujeres Libres en el Máster de Género, dándose que incluso gran parte del movimiento feminista desconoce que el aborto fue legalizado por primera vez en España, durante los años de la Guerra Civil, por la cenetista Federica Montseny como Ministra de Sanidad.

(14) Por ejemplo, en Apple, 1987; pp, 17-51 o en García y Olmeda, 2015; pp. 73-84.

\section{Referencias}

Apple, M. W. (1987). Educación y poder. Barcelona: Paidós.

Cardona, A. y Cardona, F. L. (1977). La utopía perdida. Barcelona: Bruguera.

Castro, L. (2008). Héroes y caídos. Políticas de memoria en la España Contemporánea. Madrid: Catarata.

Cuevas Noa, F. (2003). Anarquismo y educación. La propuesta sociopolítica de la pedagogía libertaria. Madrid: Fundación Anselmo Lorenzo.

Diez, A. (2003). Orígenes del cambio regional. Un turno del Pueblo. Aragón 1900-1938. Madrid: UNED. Escrivá, C. (2011). El internado-escuela "Durruti".
1937-1939. Valencia: L'Eixam Edicions.

Escrivá, C. \& Maestre, R. (2012). Cultura para todos. El movimiento libertario y la educación, 1936-1939. Valencia: L'Eixam Edicions.

García, H. y Olmeda, A. (2015). Aprendiendo a obedecer. Crítica del sistema de enseñanza. Madrid: La neurosis o las barricadas.

Gutiérrez, J. L. (1998). Se nace Hombre Libre. La obra literaria de Vicente Ballester. Cádiz: Diputación de Cádiz

-(2008). El Estado frente a la Anarquía. Los grandes procesos contra el anarquismo español (1883-1982). Madrid: Síntesis

-(2005). José Sánchez Rosa, maestro y anarquista andaluz (1864-1936). Tréveris

Kelsey, G. (1994). Anarconsindicalismo y Estado en Aragón. 1930-1938 ¿Orden Público o Paz Pública? Zaragoza: Diputación de Zaragoza - Fundación Salvador Seguí.

Marín, D. (2010). Anarquistas. Un siglo de movimiento libertario en España. Barcelona: Ariel.

Madrip, P. (2006). "La cultura anarquista en los albores del siglo XX", Madrid: Germinal. Revista de estudios libertarios, 2; 3-13.

Tomassi, T. (1988). Breviario del pensamiento educativo libertario. Cali (Colombia): Madre Tierra.

Bibliografía específica de libros texto:

Álvarez, L., Aróstegui, J., García, M., Gatell, C., Palafox, J. y Risques, M. (2012). Historia de España. $2^{\circ}$ Bahillerato. Vicens Vives.

Anónimo (2011). Demos. Ciencias Sociales, Historia. Cuaderno para la Diversidad. $4^{\circ}$ ESO. Vicens Vives.

Aróstegui, J., García, M., Gatell, C., Palafox, 


\section{1/: Anarquismo en la educación, educación en el anarquismo. Una aproximación}

\section{Divulgatio}

J. y Risques, M. (2012): Historia del mundo contemporáneo $1^{\mathrm{o}}$ Bachillerato. Barcelona: Vicens Vives.

Burgos, M., Muñoz-Delgado, M. C. (2008). Historia. Ciencias Sociales. $4^{\circ}$ ESO. Madrid: Anaya.

-(2016): Historia. Ciencias Sociales. $4^{\circ}$ ESO. Madrid: Anaya.

Díaz, M., Fernández, Ma . I., Jiménez, M., Del Pino, F. y Vidal, B. (2008). Historia. $4^{\circ}$ ESO. Madrid: Oxford University Press.

García, M., Gatell, C. (2012). Ciencias Sociales, Historia. Nuevo Demos. $4^{\circ}$ ESO. Barcelona: Vicens Vives.
García De Cortázar, J. A., Burdiel, I., Cruz, Mª Villares, R. y Redero, M. (2003). Historia de España. $2^{\circ}$ Bachillerato. Madrid: Santillana.

Grence, T., Perales, P., Rubalcaba, R., Caballero, J. M., Espino, O., Iniesta, J., López, T. y Medina, V. (2008): Historia. $4^{\circ}$ ESO. Madrid: Santillana.

Matesanz, J, Peludo, Ma. R., Sánchez, P., Sinatti, G. (2008). Historia. $4^{\circ}$ ESO. Madrid: Editex.

Sánchez, F. (1999). Historia del mundo contemporáneo. $1^{\circ}$ Bachillerato. Madrid: Oxford University Press. 